\title{
Integrated Synthesis of Thienyl Thioethers and Thieno[3,2-b] thiophenes via 1-Benzothiophen-3(2H)-ones
}

\author{
Koichi Mitsudo*a (D) \\ Nanae Habara ${ }^{a}$ \\ Yoshiaki Kobashia \\ Yuji Kurimoto ${ }^{a}$ \\ Hiroki Mandaib \\ Seiji Suga*a \\ a Division of Applied Chemistry, Graduate School of Natural Science and \\ Technology, Okayama University, 3-1-1 Tsushima-naka, Kita-ku, Okayama \\ 700-8530, Japan \\ mitsudo@cc.okayama-u.ac.jp \\ suga@cc.okayama-u.ac.jp \\ ${ }^{b}$ Department of Pharmacy, Faculty of Pharmacy, Gifu University of Medical \\ Science, 4-3-3 Nijigaoka, Kani, Gifu 509-0293, Japan
}

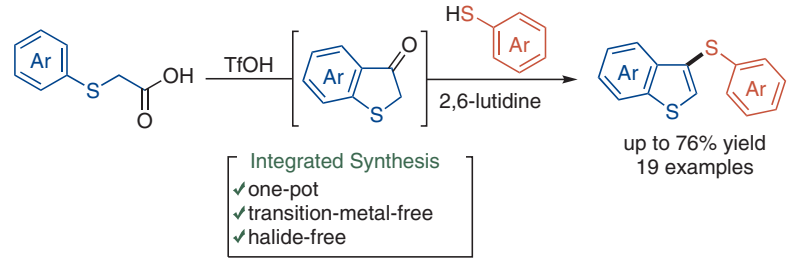

novel $\mathrm{C}-\mathrm{S}$ coupling reactions have been explored to avoid the use of these harsh and toxic reaction conditions. ${ }^{6-8}$ For example, Glorius and co-workers reported a Co-catalyzed dehydrogenative $\mathrm{C}-\mathrm{S}$ coupling of indoles and thiols. ${ }^{6 a}$ Lei and co-workers established an electrochemical dehydrogenative $\mathrm{C}-\mathrm{S}$ coupling reaction between indoles and thiols. ${ }^{7 \mathrm{a}}$ Light-driven $\mathrm{C}-\mathrm{S}$ coupling reactions have also been described; $^{8}$ for example, the Miyake group reported a visiblelight-driven $\mathrm{C}-\mathrm{S}$ coupling between aryl halides and arylthiols. ${ }^{8 a}$

(a) Conventional synthesis of thienyl thioethers

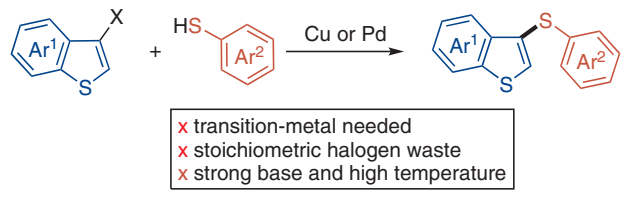

(b) Integrated synthesis via 3-benzo[b]thiophenone (this work)

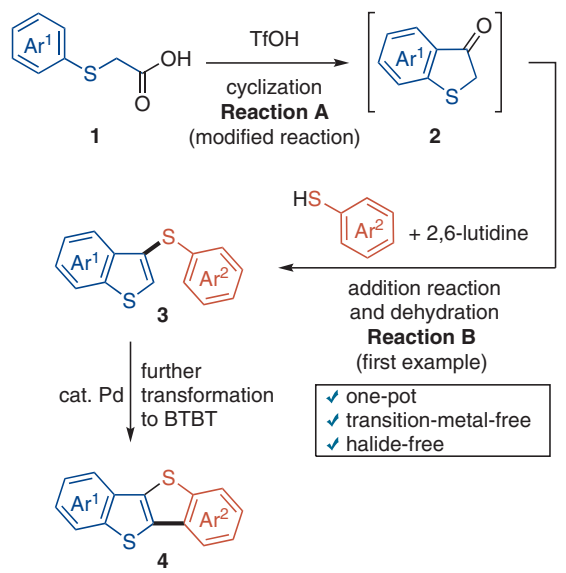

Scheme 1 Representative synthesis of thienyl thioethers 
There have also been a few reports on halogen- and transition-metal-free $\mathrm{C}-\mathrm{S}$ bond-formation reactions for the construction of thienyl thioethers. ${ }^{9}$ For example, Johnson and co-workers reported a TsOH-promoted thioether synthesis from 7-bromo-3-hydroxybenzo[b]thiophenes. ${ }^{9 a}$ Procter and co-workers reported syntheses of thioethers, including thienyl thioethers, by $\mathrm{Tf}_{2} \mathrm{O}$-mediated $\mathrm{C}-\mathrm{H}$ thiolations of arenes by methyl sulfoxides. ${ }^{9 b}$ Yorimitsu and coworkers developed acid-anhydride-promoted sulfanylation reactions of aryl sulfoxides ${ }^{9 c}$ However, methods for synthesizing thienyl thioethers under halogen- and transitionmetal-free conditions remain limited, and a novel and general method to access thienyl thioethers is attractive and in demand.

To accomplish this, we focused on 1-benzothiophen$3(2 \mathrm{H})$-ones $\mathbf{2}$, which are known to be readily available from arylthioacetic acids $\mathbf{1}$ through intramolecular Friedel-Crafts cyclization (Scheme 1b, Reaction A), ${ }^{10}$ and we designed a novel integrated sequential approach. ${ }^{11}$ We expected that 2 could then be converted into 1-benzothien-3-yl thioethers 3 through Brønsted acid catalyzed addition of arylthiols and subsequent dehydration (Scheme 1b, Reaction B). Here, we report an integrated reaction system that combines Reactions A and B for the synthesis of thienyl thioethers. The products were successfully employed in Pd-catalyzed dehydrogenative cyclization reactions to give thienoacene derivatives 4.

We first examined the thioetherification of 1-benzothiophen-3(2H)-one (2a) with 4-methylbenzenethiol (Reaction B) in the presence of various Brønsted acids, a key step to complete our strategy (Table 1 ). The desired reaction did not occur when acetic acid, trichloroacetic acid, or tri-

Table 1 Optimization of Reaction B: Thioetherification of 1-Benzothiophen-3(2H)-one (2a) with Various Brønsted Acids ${ }^{\mathrm{a}}$

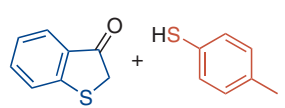

2a

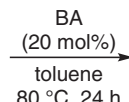

$80^{\circ} \mathrm{C}, 24 \mathrm{~h}$

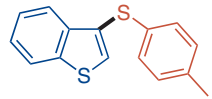

3a

\begin{tabular}{|c|c|c|c|}
\hline Entry & Brønsted acid & Conversion ${ }^{\mathrm{b}}(\%)$ & Yield $^{\mathrm{b}}(\%)$ of $3 \mathrm{a}$ \\
\hline 1 & $\mathrm{AcOH}$ & 9 & $N^{c}$ \\
\hline 2 & $\mathrm{CCl}_{3} \mathrm{CO}_{2} \mathrm{H}$ & 19 & ND \\
\hline 3 & $\mathrm{CF}_{3} \mathrm{CO}_{2} \mathrm{H}$ & 9 & ND \\
\hline 4 & $\mathrm{H}_{3} \mathrm{PO}_{4}$ & 17 & 6 \\
\hline 5 & $\mathrm{MsOH}$ & $>95$ & 65 \\
\hline 6 & TfOH & $>95$ & 63 \\
\hline 7 & $\mathrm{TsOH} \cdot \mathrm{H}_{2} \mathrm{O}$ & $>95$ & $70(63)^{d}$ \\
\hline \multicolumn{4}{|c|}{$\begin{array}{l}\text { a Reaction conditions: } 1 \mathrm{a}(0.20 \mathrm{mmol}) \text {, Brønsted acid ( } 20 \text { mol\%), toluene } \\
(0.2 \mathrm{M}), 80^{\circ} \mathrm{C}, 24 \mathrm{~h} \text {. } \\
\text { b Determined by }{ }^{1} \mathrm{H} \text { NMR with 1,1,2,2-tetrachloroethane as an internal } \\
\text { standard. } \\
{ }^{\mathrm{C}} \mathrm{ND}=\text { Not detected. } \\
{ }^{\mathrm{d}} \text { Isolated yield. }\end{array}$} \\
\hline
\end{tabular}

fluoroacetic acid was used (Table 1, entries 1-3). Although thioetherification proceeded with $\mathrm{H}_{3} \mathrm{PO}_{4}$, the desired compound 3a was obtained in only 6\% yield (entry 4 ). Further optimization revealed that sulfonic acids were suitable for thioetherification and that $\mathrm{MsOH}, \mathrm{TfOH}$, and $\mathrm{TsOH} \cdot \mathrm{H}_{2} \mathrm{O}$ afforded $3 a$ in yields of 65,63 , and $70 \%$, respectively (entries 5-7).

Because 1-benzothiophen-3(2H)-one (2a) is relatively unstable in air and gradually decomposes, we sought to prepare the reactant in situ, and we developed a one-pot reaction involving a Friedel-Crafts-type cyclization of $\mathbf{1 a}$ to afford 2a (Reaction A), followed by its thioetherification to give thioether 3a (Reaction B) (Table 2). Among the Brønsted acids examined, only TfOH was effective for both Reaction A and Reaction B [Table 1 and Supporting Information (SI), Table S1]. Phenylthioacetic acid (1a) was treated with $\mathrm{TfOH}$ (8.0 equiv) at $40{ }^{\circ} \mathrm{C}$ for three hours to give 1-benzothiophen-3(2H)-one (2a). The reaction mixture was then cooled to $0{ }^{\circ} \mathrm{C}, 4$-methylbenzenethiol and a base (7.6 equiv) were added, and the mixture was heated at $80^{\circ} \mathrm{C}$ for $18 \mathrm{~h}$. A base was essential for the formation of the desired product. Without the addition of a base, Reaction B did not proceed, and 3a was not obtained (Table 2, entry 1 ), probably because the interaction of 4-methylbenzenethiol and the excess TfOH decreased the nucleophilicity of the thiol. To neutralize excess $\mathrm{TfOH}$, we examined the addition of various bases (entries 2-6). ${ }^{12}$ As expected, the addition of DIPEA promoted the desired reaction (entries 2 and 3). Aniline was not effective, probably because it was insufficiently basic (entry 4). The order of addition of the thiol and DIPEA

Table 2 One-Pot Synthesis of Thioether 3a via 1-Benzothiophen$3(2 \mathrm{H})$-one (2a) with Various Bases ${ }^{\mathrm{a}}$

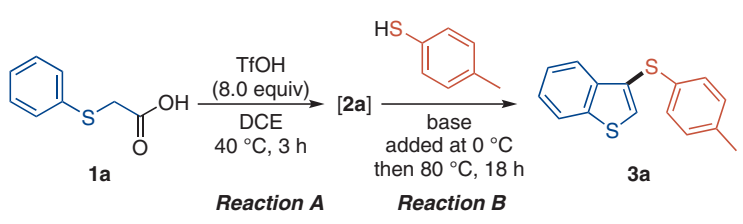

\begin{tabular}{lll}
\hline Entry & Base & Yield $^{\mathrm{b}}(\%)$ of 3a \\
\hline 1 & none & $\mathrm{ND}^{\mathrm{c}}$ \\
$2^{\mathrm{d}}$ & $i-\mathrm{Pr}_{2} \mathrm{NEt}$ & 32 \\
3 & $i-\mathrm{Pr}_{2} \mathrm{NEt}$ & 64 \\
4 & aniline & 32 \\
5 & piperidine & 65 \\
$6^{\mathrm{e}}$ & 2,6-lutidine & $67(63)^{\mathrm{f}}$ \\
\hline
\end{tabular}

a Reaction conditions: Reaction A: 1 a $(0.20 \mathrm{mmol})$, TfOH (8.0 equiv), DCE $(0.66 \mathrm{M}), 40^{\circ} \mathrm{C}, 3 \mathrm{~h}$. Reaction B: 4 -methylbenzenethiol (1.0 equiv) and base (7.6 equiv) added at $0{ }^{\circ} \mathrm{C}$, then $80^{\circ} \mathrm{C}, 18 \mathrm{~h}$.

${ }^{\mathrm{b}}$ Yield from 1a, determined by ${ }^{1} \mathrm{H}$ NMR.

${ }^{\mathrm{c}} \mathrm{ND}=$ not detected.

${ }^{d}$ Reaction B; base added before 4-methylbenzenethiol.

e Performed with TfOH (7.7 equiv).

f Isolated yield. 


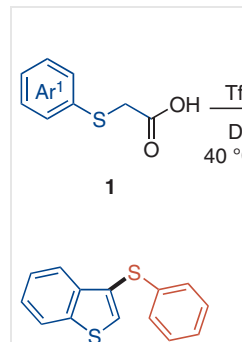

3b, $54 \%^{a}$

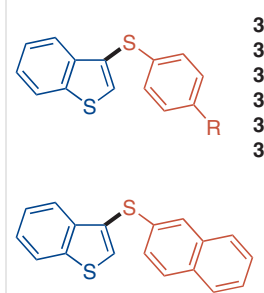

3I, N.D.

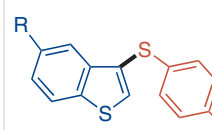

$=1$

\section{3o $(\mathrm{R}=\mathrm{Me}), 72 \%^{\mathrm{a}}(77 \%)^{\mathrm{e}}$ $3 p(R=B r), 22 \%$} 3q $(R=C l), 14 \%$

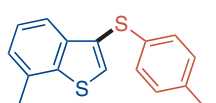

3s, $53 \%$

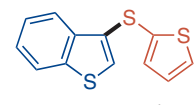

$3 \mathrm{~m}, 31 \%^{\mathrm{d}}$
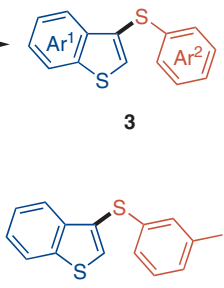

3d, $47 \%$

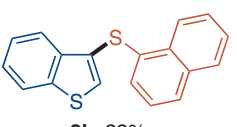

3k, $22 \%$

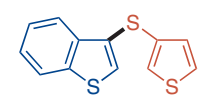

3n, $53 \%$

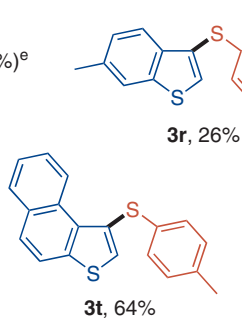

Scheme 2 One-pot syntheses of thienyl thioethers 3. Reagents and conditions: Reaction A: 1 ( $0.20 \mathrm{mmol})$, TfOH (7.7 equiv), DCE (0.66 M), $40{ }^{\circ} \mathrm{C}, 3 \mathrm{~h}$. Reaction $\mathrm{B}$ : arylthiol (1.0 equiv), 2,6-lutidine (7.4 equiv) added at $0{ }^{\circ} \mathrm{C}$, then at $80^{\circ} \mathrm{C}, 18 \mathrm{~h}$. Yields are isolated yields based on $1 .{ }^{\text {a }}$ Thiol (1.2 equiv). ${ }^{\mathrm{b}} 2$,6-lutidine (7.6 equiv). ${ }^{\mathrm{c}} 2,6$-Lutidine was added before the thiol at $-78^{\circ} \mathrm{C}$. ${ }^{\mathrm{d}} 2,6$-Lutidine was added before the thiol at 0 ${ }^{\circ} \mathrm{C} .{ }^{\mathrm{e}} 1.5 \mathrm{mmol}$ scale. ${ }^{\mathrm{f}} 0.4 \mathrm{mmol}$ scale.

affected the yield of the desired compound 3a (SI; Scheme S1). When DIPEA was added first, 3a was obtained in only $32 \%$ yield, due to the competing aldol condensation of $2 \mathbf{a}$ to form the dimer 2,3'-bi-1-benzothiophene-3-ol (entry 2). When 4-methylbenzenethiol was added before DIPEA, the side reaction was suppressed, and the yield of 3a increased to $64 \%$ (entry 3 ). We next examined several bases, and we found that 2,6-lutidine gave the best result (67\% NMR yield and $63 \%$ isolated yield; entry 6$).{ }^{13}$

By using the optimized conditions, a series of thienyl thioethers were synthesized (Scheme 2). Thioetherification with phenylthiol gave thioether $\mathbf{3 b}$ in $54 \%$ yield, whereas 2and 3-methylbenzenethiol gave the corresponding thioethers $\mathbf{3 c}$ and $\mathbf{3 d}$ in moderate yields. Next, several $p$-substituted benzenethiols were used in the reaction $(\mathbf{3 e - j})$. 4Chlorobenzenethiol and 4-bromobenzenethiol gave the halogenated thioethers $\mathbf{3 e}$ and $\mathbf{3 f}$ in yields of 40 and $43 \%$, respectively. However, 4-nitrobenzenethiol, gave a low yield of thioether $\mathbf{3 g}(21 \%)$, due to its low nucleophilicity. $\mathrm{N}$-(4Sulfanylphenyl)acetamide gave aryl thioether $\mathbf{3 h}$ in $45 \%$ yield. Benzenethiols containing electron-donating groups were also effective reactants: 4-(diphenylamino)- and 4methoxybenzenethiol gave the corresponding biaryl thioethers $\mathbf{3 i}$ and $\mathbf{3} \mathbf{j}$ in yields of 52 and 76\%, respectively. Thioetherification also proceeded successfully with naphthalene-1-thiol (3k; 22\% yield). In contrast, however, naphthalene-2-thiol failed to yield the desired compound; although the reason is unclear, nucleophilic attack by naphthalene-2thiol did not proceed. Hetaryl thiols also reacted successfully. Thioetherification with thiophene-2-thiol and thiophene-3-thiol gave the corresponding dithienyl thioethers 3m and $\mathbf{3 n}$ in yields of 31 and 53\%, respectively. One advantage of this reaction is that it is easy to introduce a substituent onto the benzothiophene skeleton because substituted precursors are readily available. Several substituted thienyl thioethers 3o-s were obtained from the corresponding substituted precursors 1. Beneficially, this protocol provides easy access to highly $\pi$-expanded thioethers, such as $\mathbf{3 t}$.

To clarify the mechanism of Reaction B, density functional theory (DFT) calculations were performed. Based on these calculations, a plausible mechanism is proposed (Scheme 3). ${ }^{14}$ First, the carbonyl group of 1-benzothiophen$3(2 \mathrm{H})$-one is protonated by TfOH while a second oxygen atom of TfOH coordinates to the $\mathrm{SH}$ proton of benzenethiol to form complex IM1. Next, the benzenethiol sulfur atom attacks the carbonyl group to afford IM2 via an eight-membered cyclic concerted transition state TS1. ${ }^{15} \mathrm{TfOH}$-assisted dehydration of IM3 proceeds via an eight-membered cyclic transition state TS2 to afford the cationic intermediate IM4. Finally, IM4 is deprotonated to form the desired thienyl thioether via transition state TS3. The calculated activation energy $\left(E_{\mathrm{a}}\right)$ of TS2 $\left(E_{\mathrm{a}}=15.7 \mathrm{kcal} \mathrm{mol}^{-1}\right)$ is higher than those of TS1 $\left(E_{\mathrm{a}}=10.5 \mathrm{kcal} \mathrm{mol}^{-1}\right)$ and TS3 $\left(E_{\mathrm{a}}=4.1 \mathrm{kcal} \mathrm{mol}^{-1}\right)$, suggesting that the $\mathrm{C}-\mathrm{O}$ bond cleavage is the rate-determining step of this reaction.

Table 3 Effect of 2,6-Lutidine on the Pd-Catalyzed Dehydrogenative Cyclization of $3 \mathbf{0}^{\mathrm{a}}$

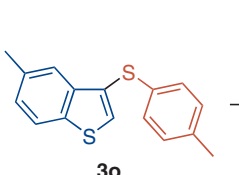

Pd(OPiv) $)_{2}(10$ mol\%)

AgOPiv (3.0 equiv)

30

PivOH $(0.1 \mathrm{M})$

$170^{\circ} \mathrm{C}, 24 \mathrm{~h}$

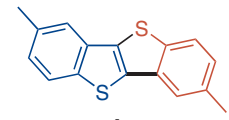

40

\begin{tabular}{lll}
\hline Entry & $\begin{array}{l}\text { 2,6-Lutidine } \\
\text { (equiv) }\end{array}$ & Recovery \\
\end{tabular}

\begin{tabular}{llll}
\hline 1 & 0 & trace & 35 \\
2 & 1.0 & $\mathrm{ND}^{\mathrm{c}}$ & 54 \\
3 & 3.0 & $\mathrm{ND}$ & 72 \\
4 & 5.0 & $\mathrm{ND}$ & 88 \\
\hline
\end{tabular}

a Reaction conditions: 30 (0.15 mmol), Pd(OPiv) 2 (10 mol \%), AgOPiv (3.0 equiv), 2,6-lutidine ( $0-5.0$ equiv), $\mathrm{PivOH}(0.1 \mathrm{M}), 170^{\circ} \mathrm{C}, 24 \mathrm{~h}$.

$\mathrm{b}$ Isolated yield.

' ND = not detected. 


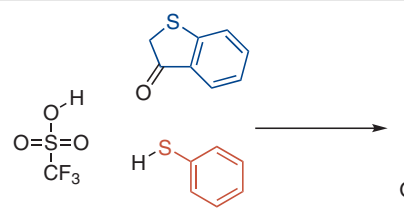

$\Delta G=(0.0)$ $/ \mathrm{kcal} \mathrm{\textrm {mol } ^ { - 1 }}$
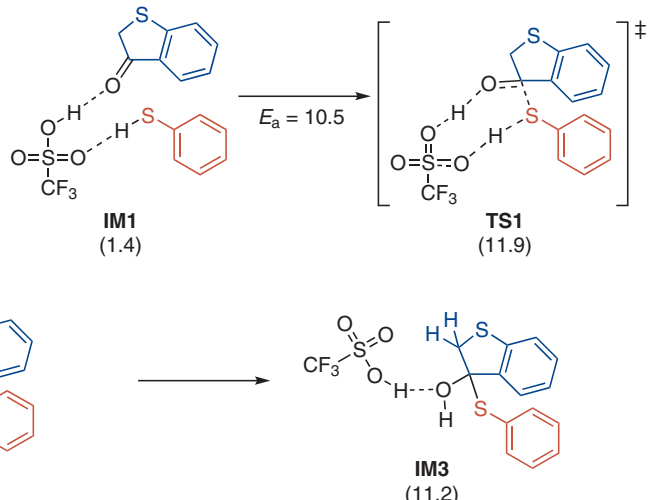

(11.2)<smiles></smiles>

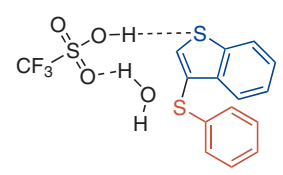

M5

(7.7)

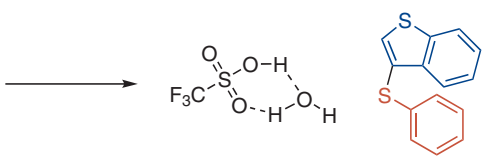

catalyst and product

$$
(-3.9)
$$

Scheme 3 A plausible mechanism for Reaction B. Gibbs free energies in $\mathrm{kcal} \mathrm{mol}^{-1}$ are shown in parentheses.

We next focused on the transformation of thienyl thioethers into BTBT derivatives by Pd-catalyzed dehydrogenative cyclization. Pd-catalyzed dehydrogenative coupling has been established as a powerful method for the formation of heteroacenes. ${ }^{16}$ However, to the best of our knowledge, this method has not been used for the efficient dehydrogenative construction of thiophene rings. Compound 30 was used as a model to examine Pd-catalyzed dehydrogenative coupling (Table 3). Benzothiophene 30 was heated at $170{ }^{\circ} \mathrm{C}$ for 24 hours in the presence of $\mathrm{Pd}(\mathrm{OPiv})_{2}(10 \mathrm{~mol} \%)$ and AgOPiv (3.0 equiv). We found that the addition of 2,6-lutidine was essential for the reaction. In the absence of 2,6-lutidine, the desired compound $\mathbf{4 0}$ was obtained in only $35 \%$ yield (Table 3 , entry 1). ${ }^{17}$ The yield of 40 increased as the amount of 2,6lutidine increased. With 1.0 equivalents of 2,6-lutidine, the yield of $\mathbf{4 0}$ was $54 \%$ yield (entry 2); this increased to $88 \%$ with 5.0 equivalents of 2,6-lutidine (entry 4 ). Although the role of 2,6-lutidine is not yet clear, it is likely to interact with the Pd catalyst and suppress $\mathrm{C}-\mathrm{S}$ bond fission.

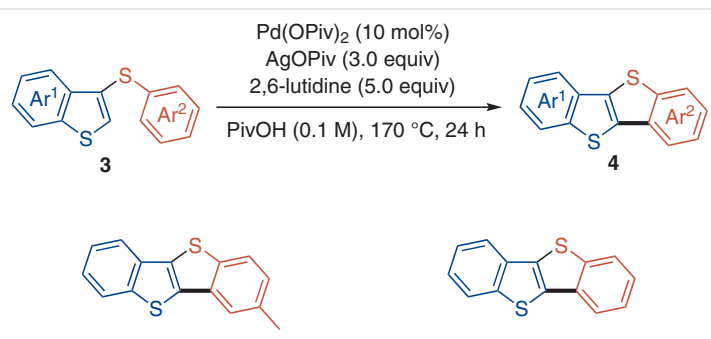

$4 a$

$65 \%(50 \%)^{a}$

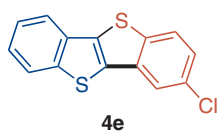

$63 \%(39 \%)^{a}$ 4b

$65 \%(39 \%)^{\mathrm{a}}$

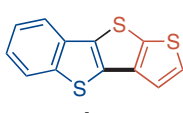

$4 \mathrm{~m}$

$30 \%$
Scheme 4 Synthesis of several BTBT derivatives under the optimized

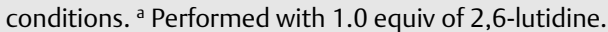




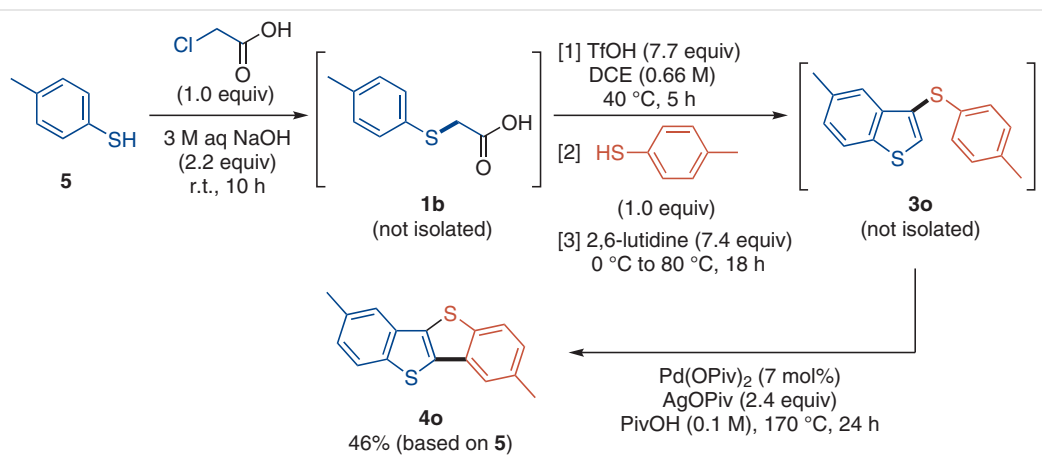

Scheme 5 Telescoped synthesis of $\mathbf{4 0}$ from 4-methylbenzenethiol (5)

By using the optimized conditions, several BTBT derivatives were synthesized (Scheme 4). BTBT (4b) and substituted BTBTs $\mathbf{4 a}$ and $\mathbf{4 e}$ were readily obtained. The advantages of this method are (i) a ready introduction of substituents and (ii) easy replacement of the benzene ring by heterocycles such as thiophene $(\mathbf{4 m})$.

Finally, we examined a telescoped synthesis of $\mathbf{4 0}$ from 4-methylbenzenethiol (5) (Scheme 5). A solution of 5 in $3 \mathrm{M}$ aqueous $\mathrm{NaOH}$ was treated with chloroacetic acid to afford 1b. The reaction was quenched with aqueous $\mathrm{HCl}$ and extracted with $\mathrm{CHCl}_{3}$. After removal of the solvent, the crude product was used in the one-pot procedure without further purification to afford a crude solution of 3o, which was quenched with saturated aqueous $\mathrm{NaHCO}_{3}$ and extracted with $\mathrm{CHCl}_{3}$. After removal of the solvent, the crude mixture was used in the Pd-catalyzed dehydrogenative reaction to afford the desired BTBT derivative 40 in an $46 \%$ overall yield. ${ }^{18}$ This result suggests that our protocol can be used to prepare a variety of thienyl thioethers and BTBT derivatives from easily accessible chloroacetic acid and the appropriate arylthiol.

In conclusion, we have developed a transition-metalfree and halide-free one-pot synthesis of thienyl thioethers. Several novel thioethers were readily synthesized by using the optimized conditions. An efficient conversion of the thioethers into thienothiophenes was also established. We also demonstrated a telescoped synthesis of a thienothiophene from an arylthiol. This strategy permits the efficient and easy synthesis of 3-benzo[b]thienyl thioethers and thienothiophenes. Further applications of this strategy are currently being investigated in our laboratory.

\section{Funding Information}

This work was supported in part by JSPS KAKENHI grants numbers JP16K05695, JP16K05777, JP19K05477, JP19K05478, and JP18H04455 in Middle Molecular Strategy, and by the Okayama Foundation for Science and Technology.

\section{Supporting Information}

Supporting information for this article is available online at https://doi.org/10.1055/s-0040-1707280.

\section{References and Notes}

(1) Feng, M.; Tang, B.; Liang, S. H.; Jiang, X. Curr. Top. Med. Chem. (Sharjah, United Arab Emirates) 2016, 16, 1200.

(2) (a) Li, L.; Zhao, C.; Wang, H. Chem. Rec. 2016, 16, 797. (b) Cinar, M. E.; Ozturk, T. Chem. Rev. 2015, 115, 3036. (c) Takimiya, K.; Osaka, I.; Mori, T.; Nakano, M. Acc. Chem. Res. 2014, 47, 1493. (d) Takimiya, K.; Nakano, M.; Kang, M. J.; Miyazaki, E.; Osaka, I. Eur. J. Org. Chem. 2013, 217. (e) Takimiya, K.; Shinamura, S.; Osaka, I.; Miyazaki, E. Adv. Mater. (Weinheim, Ger.) 2011, 23, 4347.

(3) (a) Bunker, A. M.; Edmunds, J. J.; Berryman, K. A.; Walker, D. M.; Flynn, M. A.; Welch, K. M.; Doherty, A. M. Bioorg. Med. Chem. Lett. 1996, 6, 1367. (b) Sall, D. J.; Bailey, D. L.; Bastian, J. A.; Buben, J. A.; Chirgadze, N. Y.; Clemens-Smith, A. C.; Denney, M. L.; Fisher, M. J.; Giera, D. D.; Gifford-Moore, D. S.; Harper, R. W.; Johnson, L. M.; Klimkowski, V. J.; Kohn, T. J.; Lin, H.-S.; Takeuchi, K.; Toth, J. E.; Zhang, M. J. Med. Chem. 2000, 43, 649.

(4) (a) Yuan, Y.; Giri, G.; Ayzner, A. L.; Zoombelt, A. P.; Mannsfeld, S. C. B.; Chen, J.; Nordlund, D.; Toney, M. F.; Huang, J.; Bao, Z. Nat. Commun. 2014, 5, 3005. (b) Niebel, C.; Kim, Y.; Ruzié, C.; Karpinska, J.; Chattopadhyay, B.; Schweicher, G.; Richard, A.; Lemaur, V.; Olivier, Y.; Cornil, J.; Kennedy, A. R.; Diao, Y.; Lee, W.-Y.; Mannsfeld, S.; Bao, Z.; Geerts, Y. H.J. Mater. Chem. C 2015, 3, 674. (c) Grigoriadis, C.; Niebel, C.; Ruzié, C.; Geerts, Y. H.; Floudas, G. J. Phys. Chem. B 2014, 118, 1443. (d) Ebata, H.; Izawa, T.; Miyazaki, E.; Takimiya, K.; Ikeda, M.; Kuwabara, H.; Yui, T. J. Am. Chem. Soc. 2007, 129, 15732.

(5) (a) Beletskaya, I. P.; Ananikov, V. P. Chem. Rev. 2011, 111, 1596. (b) Lee, C.-F.; Liu, Y.-C.; Badsara, S. S. Chem. Asian J. 2014, 9, 706.

(6) For representative examples of transition-metal-catalyzed dehydrogenative $\mathrm{C}-\mathrm{S}$ coupling reactions, see: (a) Gensch, T.; Klauck, F. J.; Glorius, F. Angew. Chem. Int. Ed. 2016, 55, 11287. (b) Xu, W.; Hei, Y.-Y.; Song, J.-L.; Zhan, X.-C.; Zhang, X.-G.; Deng, C.-L. Synthesis 2019, 51, 545. (c) Wang, X.; Yi, X.; Xu, H.; Dai, H.X. Org. Lett. 2019, 21, 5981. (d) Tian, L.-L.; Lu, S.; Zhang, Z.-H.; Huang, E.-L.; Yan, H.-T.; Zhu, X.-J.; Hao, X.-Q.; Song, M.-P. J. Org. Chem. 2019, 84, 5213. (e) Nishino, K.; Tsukahara, S.; Ogiwara, Y.; Sakai, N. Eur. J. Org. Chem. 2019, 1588. (f) Lu, S.; Zhu, Y.-S.; Yan, K.-X.; Cui, T.-W.; Zhu, X.-J.; Hao, X.-Q.; Song, M.-P. Synlett 2019, 30, 1924. (g) Kang, Y.-S.; Zhang, P.; Li, M.-Y.; Chen, Y.-K.; Xu, H.- 
J.; Zhao, J.; Sun, W.-Y.; Yu, J.-Q.; Lu, Y. Angew. Chem. Int. Ed. 2019, 58, 9099. (h) Jiang, Y.; Feng, Y.-y.; Zou, J.-X.; Lei, S.; Hu, X.l.; Yin, G.-f.; Tan, W.; Wang, Z. J. Org. Chem. 2019, 84, 10490. (i) Gu, L.; Fang, X.; Weng, Z.; Song, Y.; Ma, W. Eur. J. Org. Chem. 2019, 1825. (j) Li, M.; Wang, J. Org. Lett. 2018, 20, 6490.

(7) For electrochemical C-S coupling reactions, see: (a) Wang, P.; Tang, S.; Huang, P.; Lei, A. Angew. Chem. Int. Ed. 2017, 56, 3009. (b) Ogawa, K. A.; Boydston, A. J. Org. Lett. 2014, 16, 1928. (c) Wang, P.; Tang, S.; Lei, A. Green Chem. 2017, 19, 2092. (d) Liu, D.; Ma, H.-X.; Fang, P.; Mei, T.-S. Angew. Chem. Int. Ed. 2019, 58, 5033. (e) Liang, S.; Zeng, C.-C.; Tian, H.-Y.; Sun, B.-G.; Luo, X.-G.; Ren, F. Adv. Synth. Catal. 2018, 360, 1444. (f) Folgueiras-Amador, A. A.; Qian, X.-Y.; Xu, H.-C.; Wirth, T. Chem. Eur.J. 2018, 24, 487. (g) Huang, C.; Qian, X.-Y.; Xu, H.-C. Angew. Chem. Int. Ed. 2019, 58, 6650. (h) Mitsudo, K.; Matsuo, R.; Yonezawa, T.; Inoue, H.; Mandai, H.; Suga, S. Angew. Chem., Int. Ed. 2020, 59, 7803.

(8) For light-driven C-S coupling reactions, see: (a) Liu, B.; Lim, C.H.; Miyake, G. M. J. Am. Chem. Soc. 2017, 139, 13616. (b) Hong, B.; Lee, J.; Lee, A. Tetrahedron Lett. 2017, 58, 2809. (c) Kibriya, G.; Mondal, S.; Hajra, A. Org. Lett. 2018, 20, 7740. (d) Liu, B.; Lim, C.-H.; Miyake, G. M. Synlett 2018, 29, 2449. (e) Li, G.; Yan, Q.; Gan, Z.; Li, Q.; Dou, X.; Yang, D. Org. Lett. 2019, 21, 7938. (f) Li, R.; Shi, T.; Chen, X.-L.; Lv, Q.-Y.; Zhang, Y.-L.; Peng, Y.-Y.; Qu, L.B.; Yu, B. New J. Chem. 2019, 43, 13642. (g) Blank, L.; Fagnoni, M.; Protti, S.; Reuping, M. Synthesis 2019, 51, 1243. (h) Shieh, Y.C.; Du, K.; Basha, R. S.; Xue, Y.-J.; Shih, B.-H.; Li, L. J. Org. Chem. 2019, 84, 6223.

(9) (a) Ahmed, M.; Briggs, M. A.; Bromidge, S. M.; Buck, T.; Campbell, L.; Deeks, N. J.; Garner, A.; Gordon, L.; Hamprecht, D. W.; Holland, V.; Johnson, C. N.; Medhurst, A. D.; Mitchell, D. J.; Moss, S. F.; Powles, J.; Seal, J. T.; Stean, T. O.; Stemp, G.; Thompson, M.; Trail, B.; Upton, N.; Winborn, K.; Witty, D. R. Bioorg. Med. Chem. Lett. 2005, 15, 4867. (b) Fernández-Salas, J. A.; Pulis, A. P.; Procter, D. J. Chem. Commun. 2016, 52, 12364. (c) Kawashima, H.; Yanagi, T.; Wu, C.-C.; Nogi, K.; Yorimitsu, H. Org. Lett. 2017, 19, 4552.

(10) For representative examples, see: (a) Werner, L. H.; Schroeder, D. C.; Ricca, S. Jr. J. Am. Chem. Soc. 1957, 79, 1675. (b) Padmavathi, V.; Padmaja, A.; Reddy, D. B. Indian J. Chem., Sect. B: Org. Chem. Incl. Med. Chem. 1999, 38, 308. (c) Reddy, D.
B.; Padmaja, A.; Reddy, M. M.; Reddy, P. V. R. Indian J. Chem., Sect. B: Org. Chem. Incl. Med. Chem. 1995, 34, 427. (d) Zweig, J. E.; Newhouse, T. R. J. Am. Chem. Soc. 2017, 139, 10956.

(11) (a) Yoshida, J.; Saito, K.; Nokami, T.; Nagaki, A. Synlett 2011, 1189. (b) Suga, S.; Yamada, D.; Yoshida, J.-i. Chem. Lett. 2010, 39, 404. (c) Bard, A. J. Integrated Chemical Systems: A Chemical Approach to Nanotechnology; Wiley: New York, 1994.

(12) Further details of the base optimizations, see SI, Table S6.

(13) 3-(4-Tolylsulfanyl)-1-benzothiophene (3a): One-Pot Synthesis; Typical Procedure

TfOH (0.136 mL, $231 \mathrm{mg}, 1.54 \mathrm{mmol})$ was added dropwise to a solution of (phenylsulfanyl)acetic acid (1a; $33.6 \mathrm{mg}, 0.20 \mathrm{mmol}$ ) in anhyd DCE $(0.3 \mathrm{~mL})$, and the resulting mixture was stirred at $40{ }^{\circ} \mathrm{C}$ for $3 \mathrm{~h}$ then cooled to $0{ }^{\circ} \mathrm{C}$. 4-Methylbenzenethiol $(24.8$ $\mathrm{mg}, 0.20 \mathrm{mmol})$ and 2,6 -lutidine $(0.18 \mathrm{~mL}, 1.5 \mathrm{mmol})$ were added, and the mixture was stirred at $80^{\circ} \mathrm{C}$ for $18 \mathrm{~h}$ then cooled to r.t. The reaction was quenched with sat. aq $\mathrm{NaHCO}_{3}(3 \mathrm{~mL})$, and the mixture was extracted with $\mathrm{CHCl}_{3}(3 \times 5 \mathrm{~mL})$. The combined organic phase was dried $\left(\mathrm{MgSO}_{4}\right)$, filtered, and concentrated under reduced pressure. The residue was purified by column chromatography (silica gel, hexane) to give a colorless liquid; yield: $32.3 \mathrm{mg}(0.13 \mathrm{mmol}, 63 \%)$.

IR (neat): 3096, 3021, 1595, 1254, $1016 \mathrm{~cm}^{-1} .{ }^{1} \mathrm{H}$ NMR (400 $\left.\mathrm{MHz}, \mathrm{CDCl}_{3}\right): \delta=2.28(\mathrm{~s}, 3 \mathrm{H}), 7.03(\mathrm{~d}, J=8.4 \mathrm{~Hz}, 2 \mathrm{H}), 7.11(\mathrm{~d}, J=$ $8.4 \mathrm{~Hz}, 2 \mathrm{H}), 7.35-7.40(\mathrm{~m}, 2 \mathrm{H}), 7.62(\mathrm{~s}, 1 \mathrm{H}), 7.78-7.83(\mathrm{~m}, 1 \mathrm{H})$, 7.86-7.90 (m, $1 \mathrm{H}) .{ }^{13} \mathrm{C}$ NMR $\left(100 \mathrm{MHz}, \mathrm{CDCl}_{3}\right): \delta=20.9,122.9$, 123.0, 124.7, 124.9, 125.0, 128.4, 129.8, 130.8, 132.5, 136.0, $138.8,140.0$

(14) For details of the calculations, see SI.

(15) Li, X.; Ye, S.; He, C.; Yu, Z.-X. Eur. J. Org. Chem. 2008, 4296.

(16) (a) Saito, K.; Chikkade, P. K.; Kanai, M.; Kuninobu, Y. Chem. Eur.J. 2015, 21, 8365. (b) Kaida, H.; Satoh, T.; Hirano, K.; Miura, M. Chem. Lett. 2015, 44, 1125. (c) Kurimoto, Y.; Mitsudo, K.; Mandai, H.; Wakamiya, A.; Murata, Y.; Mori, H.; Nishihara, Y.; Suga, S. Asian J. Org. Chem. 2018, 7, 1635. (d) Mitsudo, K.; Kurimoto, Y.; Mandai, H.; Suga, S. Org. Lett. 2017, 19, 2821.

(17) The structure of $\mathbf{4 0}$ was confirmed by X-ray crystal structure analysis. CCDC 1961314 contains the supplementary crystallographic data for compound 4o. The data can be obtained free of charge from The Cambridge Crystallographic Data Centre via www.ccdc.cam.ac.uk/getstructures.

(18) For details, see SI. 